often even the difference is divergent. Particular interest attached to a letter from H. A. Bethe who had in this way calculated a correction to the fine-structure separation of the hydrogen levels in the direction indicated by the microwave observations of Lamb and Retherford.

An early theory of the fundamental length type is the non-linear electromagnetic theory of Born and Infeld. Its practical consequences are so difficult to calculate that it is not possible to say that it has been disproved, although one would prefer a simpler description of phenomena. Another approach is to introduce a 'structure factor' for electrical particles, which can be done without conflicting with the principle of relativity only by assuming that the charge density at a given time depends on the position of the particles at other times. Such a theory can be made to avoid the classical infinities and probably the runaway solutions, but no quantization has yet proved feasible.

A more fundamental change of view is contemplated in a series of papers by Snyder, who considers a 'quantized' space-time. In his theory the space and time co-ordinates are non-commuting quantities, the eigen-values of the space co-ordinates being discrete (the interval between them thereby introducing a fundamental length). The idea still needs further development; but is indicative of the radical departure from our present ideas which may be necessary.

One session was devoted to mesons. There are so many variants of the theory that it is difficult to speak of agreement with experiment, but in general it seems to be poor for scattering and Bremsstrahlung processes. The agreement is insufficient to indicate the value of the meson spin. That negative mesons stopped in carbon and other light elements have time to decay into electrons before being captured by carbon nuclei is an experimental result which challenges the theory. According to calculations of Fermi, Teller and Weisskopf, it is in conflict with the meson theory of nuclear forces; Bohr, on the other hand, has criticized their argument and suggests that there is no disagreement. Dr. Ferretti reported on more comprehensive calculations, which show how complicated the process of the stopping of mesons really is, and which, while very provisional, do indicate a conflict with experiment, though smaller than calculated by Fermi et al.

Our knowledge of mesons is still so incomplete that we do not know how many different kinds exist, nor with certainty from what particles they can be formed and into which particles they disintegrate. A report on the recent observations by the Bristol group, of mesons 'disintegrating' into other mesons, probably with the emission of another unidentified particle, and of mesons causing nuclear disruptions, was of interest in this connexion.

Two sessions were devoted to nuclear theory, including the meson theory of nuclear forces. Consequences of this theory can only be calculated quantitatively for the simplest nuclei, and agreement with experiment is poor in view of the number of variants. The theory suffers from the infinities of all field theories, which here lead to greater difficulties than in electrodynamics. There were reports on calculations of magnetic moments, photo-disintegra. tion of the deuteron, scattering of protons and neutrons and the effect of 'tensor forces', which, generally speaking, gave vague support for certain specializations of the theory. It was clear that the time is not yet ripe for detailed calculations on com- plex nuclei, although one may profitably study such problems as the possible rotations of heavy nuclei, which involve only general considerations, and the regularities of nuclear spins, which are zero for all nuclei containing an evon number of protons and of neutrons.

The conference was throughout kept on an informal level and owed much of its success to the organisation undertaken by members of the theoretical physics department of the University of Birmingham, and to the hospitality of the University, which not only gave financial aid, allowing distinguished physicists from abroad to be invited, but also entertained to dinner all members of the conference on the evening of July 25. The conference provided an ideal opportunity for the interchange of ideas, such as is often absent from a more formal conference, even though it made abundantly clear that the fundamental idea essential to further progress in physical theory is still lacking.

M. H. L. PRYCE

\section{THE WORLD FEDERATION OF SCIENTIFIC WORKERS}

\section{BY J. G. CROWTHER}

$T$ HE World Federation of Scientific Workers was founded in July 1946. It is a natural outcome of the growth of science, and of the scientific profession, in many countries. Associations of scientific workers concerned with the problems of scientists as scientists in general, rather than specialists in a particular technique, began with the foundation of the National Union of Scientific Workers in the United Kingdom in 1918. This body was originally a trade union; but it relinquished this status for about two decades, resuming it in 1941. Its name is now the Association of Scientific Workers, and it has more than eighteen thousand members. The success of the Association, with its young and widely varied membership, has made a deep impression in many countries overseas. Consequently, when the Association took the initiative in proposing a world federation of similar bodies, it found an enthusiastic response.

The World Federation of Scientific Workers already contains seventeen affiliated bodies in fourteen countries from all five continents. It is able to call on a very wide range of experience for advice.

The fundamental aim of the Federation is to strengthen the mutual aid and information between scientists in every country, so that the strength of the scientists in one country shall be the strength of all their colleagues throughout the world. It is hoped to further through the Federation the achievement of agreed opinions on those questions which affect all scientists alike, irrespective of their speciality. In this way the scientists of the world will be able to speak with one voice on matters that affect them fundamentally. Towards this end the Federation is preparing a Scientists' Charter, defining the duties and rights of scientists, which should be observed in all countries. In every place, it will be possible to compare the actual situation with that given by the Charter, and thus assist scientists everywhere with a guide to a proper status for science and scientists. The standards of education, remuneration, working conditions, opportunities for work, and the control 
and direction of science vary greatly over the surface of the globe. Scientists have special knowledge of science, and in virtue of this they have the responsibility of seeing that the public is correctly informed on scientific matters which affect public affairs.

The World Federation seeks to keep in touch, and collaborate, with other international bodies concerned with science, such as the United Nations Educational, Scientific and Cultural Organisation, and the World Federation of Trade Unions. U.N.E.S.C.O. has already invited the Federation to send an observer to one of its panels, and it has invited the Federation to send an observer, subject to confirmation by the Conference itself, to the present U.N.E.S.C.O. Conference at Mexico City.

Another direction in which the World Federation has been able to contribute towards international understanding between scientists is in collaboration with other scientific bodies in the commemoration of scientific personalities and events of international significance. It joined with the Association of Scientific Workers and the Society for Visiting Scientists to organise meetings in memory of Paul Langevin, and it has joined with the Association des Travailleurs Scientifiques and the Syndicat National de l'Enseignement Supérieur et de la Recherche Scientifique in organising, under the patronage of the President of the French Republic and the Académie des Sciences, a meeting in Paris in commemoration of the tenth anniversary of the death of Lord Ruther. ford. The occasion will be an opportunity for remembering the great physicist, and reflecting on what has come of his work, and that of his colleagues in physics. A special feature of these meetings is that they have been organised primarily by the scientists of one country in celebration of the achievements of a scientist of another country, and have thus contributed towards the strengthening and understanding of mutual dependence and sympathy in science.

The president of the World Federation of Scientific Workers is Prof. F. Joliot-Curie, and its registered headquarters are in Paris. French-speaking inquirers can most readily receive further information about the Federation from the Secrétaire Général, 47 Boulevard St. Michel, Paris V, and English-speaking inquirers from the Secretary-General, 15 Half Moon Street, London, W.1.

\section{THE PAINT RESEARCH ASSOCIATION}

\section{By DR. L. A. JORDAN Director}

$\mathrm{T}$ HE co-operative industrial research association movement in Britain is an interesting develop. ment, whatever may have been said or written about it, particularly during the last few years. Those responsible for controlling the work of the associations and of holding together on a voluntary basis a heterogeneous membership with varied views as to what co-operative industrial research is about, are conscious of the limitations and have no illusions about the weaknesses of the system. They have the responsibility of watching the interests equally of all their members; no duty could be more difficult, and errors of judgment are not lightly tolerated. Displeasure, however transient, saps enthusiasm, without which nothing is achieved; on the other hand, confidence is a plant of slow growth, but it is essential and it can be won.

One must admit that the crux of the matter, or at least one aspect of it, is the interpretation placed by individuals on the word 'co-operative' and how it is related to the primary and universal human instinct of self-interest-which may come to be regarded as self-preservation. Research work is not the only human activity in which it must be recognized that there are degrees in co-operation, and that it does not do to strain even the best of good intentions. Fortunately for research association work, many industries have a wide background of technology waiting for first-class scientific investigation from which information may be gained acceptable to all, provided it is brought only to a certain stage. That stage is when each member firm according to inclination and capacity can take the material information offered and develop it within the ambit of the firm's interest.

Inevitably that stage is too far for some-or at least they think so; definitely not far enough for others, and certainly not far enough to ensure a widespread, rapid and effective absorption of research results into the technical administration of the industry. How to deal with that problem may give rise to differing opinions and to much honest doubt. The uneasiness so frequently expressed about the research association movement is justified in so far as it is prompted by concern as to whether means can be found to give a better overall performance, meaning the integration of the results of scientific work plus development plus utilization by the greater part of an industry.

In the meantime, while such problems are being resolved, directors of research associations have to operate the instrument provided and, coming down to a homely metaphor, the 'proof of the pudding' test still holds. If one is so minded, many quite logical and apparently sound reasons can be found why the research association idea should not work out in practice; but, in fact, the associations have not done too badly. As with most human enterprises, everything turns upon the degree of satisfaction accorded to the participants, not the least important, particularly in time of war, being the State. It is true to say that had the research associations not existed in 1939, Britain would have lacked a very powerful weapon; for the associations made it possible to mobilize at short notice in industry by industry most of the scientific and technical knowledge available, and they provided facilities for the immediate investigation of new problems under most favourable conditions.

In a number of cases, particularly those concerned with the traditional industries, associations were not easy to start; thus it was not until 1926, that is, ten years after the movement began with the establishment of the Department of Scientific and Industrial Research, that the Paint Research Association was formed. The term 'paint' in this context includes colour (that is, pigments), varnish, printing ink, certain aspects of linoleum-in fact, all those procedures which depend upon a related technology of incorporating a solid into a fluid medium.

It is pertinent to ask what the Association has done during its twenty-one years and what it proposes to do-two questions which can be taken together in so far as they can be dealt with adequately in this short statement. First, there has been too 